\title{
Anatomical forms of Domestic Cat (Felis catus do- mesticus ) gall bladder in Egypt with its relation to their biliary system
}

\section{Reem R.T. ${ }^{1 *}$, Alaa H.E. ${ }^{1}$, Farghali H.A. ${ }^{2}$, Maher M.A. ${ }^{1}$}

1 Department of Anatomy and Embryology, faculty of veterinary medicine, Cairo University, Egypt.

2 Department of Surgery, Anesthesiology and Radiology, faculty of veterinary medicine, Cairo University, Egypt.

\begin{abstract}
In order to help veterinarians in application of surgical procedures in cat and detection of gall bladder disease so that, we gathered twenty-one domestic cats and concluded that three main forms were collected; single gall bladder, duplex fundus and bilobed gall bladder. Both the gall bladder forms and the hepatic ducts distribution were not related. The bile duct was constructed from the left and right hepatic ducts in addition to the cystic one. In some cases, we explored that a short common hepatic duct. Sonographically, the gall bladder appeared differ in conformance, encircled by echogenic wall and adjacent to the right medial lobe laterally and the quadrate lobe medially.
\end{abstract}

Keywords: Gall bladder, bile duct, hepatic duct, corrosive cast, cat.

\section{Introduction}

The gall bladder was situated between the right medial and quadrate lobes of

J. Vet. Anat. the liver to the right of the median plane and close to the $8^{\text {th }}$ intercostal space, and the gall bladder was seen both viscerally as well as the parietally (Dyce et al. 2010).

The differences in the forms of gall bladder congenitally may be organized from the miscarriage of vacuoliation of the gall bladder and bile duct diverticulum (Mayhew et al. 2002). Gall bladder malformations were monitored as septated gall bladder, bilobed gall bladder and Duplex gall bladder (Mahato, 2010 and Ergin et al. 2013). Also, some diseases may affect the gall bladder shape as emaciated without appetite cat would have distended rounded gall bladder (Meyer, 2013).

Using sonar devices for localizing the site of gall bladder, it was at the right cranial part of abdomen (Kook, 2013). Only the gall bladder and cystic duct can be simply monitored ultrasonographically in normal cats while the rest extrahepatic and intrahepatic structures were not detected except in 
a diseased condition (Penninck et al. 2010 and D'Anjou \& Penninck, 2015).

The gall bladder, cystic duct, bile duct and hepatic duct composed the biliary system (Center, 2009 and Kook, 2013). Three to five hepatic ducts in cats opened in to the cystic duct to form the bile duct after the fusion with the last hepatic duct (Brockman, 2013). A short common hepatic duct received the cystic duct constructing the bile duct (Budras \& Habel, 2003).

\section{Material and Methods}

The experiments were conducted by the international ethical standards set by the institutional animal care and use committee (Vet. CU. IACUC)

VetCU1111201808. The present study was constructed on twenty-one domestic cats (Felis catus domesticus) which were adult, apparently healthy of both sexes with average body weight; $2.900-3.500 \mathrm{Kg}$. The animals were euthanized using IIV10 mg/kg Diazepam. Nine cats were dissected freshly for gall bladder morphology then fixed by $10 \%$ formalin. Another nine cats were injected with colored latex neoprene into the major duodenal papilla and then fixed by freezing or by formalin overnight. Further dissection occurred and then transferred to concentrate HCL for three days. The specimens were photographed using Olympus digital camera SP-600UZ 12 mega pixel. The anatomical nomenclature used in this study was in accordance with the Nomina Anatomica Veterinaria 2017 ( $6^{\text {th }}$ edition).
We explored another 3 live cats; by using the B-mode scan (Pie medical) or Doppler device (EXAGO, Echo control medical, France) with a linear multi frequency transducer using a frequency of $7.5 \mathrm{MHz}$. After that the same cats were euthanized as mentioned for the radiological examination. For obtaining contrast X-ray films, the specimens were injected by lead oxide dissolved in turpentine oil into the major duodenal papilla. The films were taken by using the radiographic device (Fisher imaging, Chicago, USA).

\section{Results}

In the most of the gathered cat livers, the gall bladder was situated in the fossa of gall bladder more superficial between the right medial (fig.1c) and the quadrate lobes (fig. 1d) where its ends did not extend to the liver ventral margin, also appear on visceral surface only (fig. 1A). In another specimens, the gall bladder clarified on the liver parietal surface at the level of the $7^{\text {th }}$ intercostal space (Figs.1B, C, D \&2), also they were more larger in size and length to out stretch nearly to the level of the liver ventral borders .

In our work on cat gall bladder, three main forms were collected; single gall bladder, duplex fundus and bilobed gall bladder.

In most of the specimens the gall bladder was single, with different shapes; relatively large oval (Fig.3A, B) or pear shaped (Figs. 3C) or distended fundus (fig.3D) or truncated fundus (fig.3E). 
Pear shaped gall bladder (Figs. 3C) was curved with broad fundus, slightly concave hepatic surface, convex gastric surface and folded neck connected with zigzag cystic duct. The distended fundus gall bladder (fig.3D) was large and rounded joined with wide body which decreases upward to reach by the narrow neck. The truncated fundus gall bladder (fig.3E) has a shorter left fundic end and a narrow-bended neck attaching with a coiled cystic duct.

Duplex fundus gall bladder (fig. 4A) was a single gall bladder with two broad fundic parts which were divided externally only by a sagittal groove and a single body and neck. It was situated in a very deep fossa (fig. 1C) of gall bladder made by the whole the quadrate lobe and has a small part of the right medial one.

Bilobed gall bladder (fig. 4B) with both double fundus and corpus attached with single neck which narrowing gradually to join a twisting cystic duct. A huge fossa of gall bladder was surrounded viscerally by right medial and quadrate lobes and both lobes of gall bladder appeared while parietally only the ventral part of left lobe of gall bladder was viewed.

The present investigation classified the formation of the bile duct and the terminations of the hepatic ducts into two groups; The first most common where the bile duct was formed by the cystic duct with the left and right hepatic ducts (Figs.5A, B, D), The cystic duct (Figs. 5A, B, D/1) was relatively long and coiled, The left hepatic duct (Figs. 5A,B,D/3) established by the lobar ducts from both left and quadrate lobes and it received, in most cases the papillary process branch (Fig. 5D/3,8,9,10,15). The right hepatic duct (Figs. 5A, B, D/2) was established by the joining of the right medial lobar duct (from the right medial lobe) and the right lateral lobar duct (drained the right lateral lobe as well as the caudate process by the Ramus processus caudatus) (Fig. 5D/2, 5, 16, 17). It must be noted that the right hepatic duct in three specimens was only formed by the union of the right lateral and right medial lobar ducts which drained their respective lobes (Figs. 5A, B/2, 16, 17). In such conditions, the branch of the caudate process opened directly into the bile duct (Figs. 5A, B/4, 5).

In the second Group, in some specimens, the bile duct was formed by the union of the cystic duct with a short common hepatic duct (Figs. 5C, 6): The cystic duct (Figs. 5C, 6/1) was long and tortious. The common hepatic duct (Figs. 5C, 6/6) was short, established by the fusion of the left hepatic duct collected both left lobes and papillary process (Fig. 5C/3, 9, 10, 15) as well as receiving the duct of the quadrate lobe in one specimen (Fig. $6 / 8$ ), while the right hepatic duct drained the right medial lobe branch and the quadrate lobar branch (Fig. $5 \mathrm{C} / 2,8)$. In such specimens, the right lateral lobar branch and the branch of 
the caudate process fused to form what could be called duct hepatica dextra accessoria (Fig. 5C/5, 7, 17) which opened directly into the bile duct. The latter gave a very narrow ductule to the right medial lobe dorsally and laterally.

The cat bile duct (Ductus choledochus) (Figs. 6, 7/4) was relatively long, passed through the hepatoduodenal ligament (Fig. 7A/J), where it integrated with the pancreatic duct (Figs.6,7B/21) and penetrated the duodenal wall to open on the major duodenal papilla encircled by the hepatopancreatic ampulla (Figs. 6,7) 2-2.5 $\mathrm{cm}$ distal to pylorus.

\section{Discussion}

Dyce et al. (2010) summarized that the dog gall bladder was situated in the fossa of gall bladder more superficial between the right medial and the quadrate lobes of the liver and appeared on both parietal and visceral surfaces, which was similar to our observations in cat in cases of the distended gall bladder, duplex fundus and the bilobed gall bladder. Per-contra, in case of the single oval and pearshaped gall bladders, they appeared only viscerally.

In agreement with the description of Mahato (2010) and Ergin et al. (2013), those different forms of cat gall bladder were collected as the duplex fundus and bilobed gall bladder. In addition, our results on cat liver concerning the gall bladder shape were supported by Mayhew et al. (2007).
Concerning the distended fundus gall bladder which was large and rounded joined with wide body; these findings agreed with Meyer (2013) who documented that it was due to loss of appetite of cat.

It must be noted that, the liver investigated specimen of bilobed gall bladder revealed that the right lobe presented two small buds connected together; this condition was not recorded in relevant references.

Brockman (2013) determined that the common hepatic duct was not present and the lobar hepatic ducts joined individually with the cystic duct to form the dog bile duct, which was in contradiction with our conclusions that the bile duct was formed by the union of the cystic duct with a short common hepatic duct.

Similar observation of Dyce et al. (2010) that the biliary ducts drained the caudate and the right lateral lobes of the liver entered the bile duct directly. Conversely, in other collected specimens in our work the two ducts merged to form the right accessory hepatic duct, also in exceptional cases, that caudate process branch entered separately the bile duct.

The entrance of the bile and pancreatic ducts into the duodenum terminated together as observed in the cat specimens were in accordance with (Center, 2009 and Lehner \& McAnulty, 2010). Regarding the presence of the hepatopancreatic ampulla encircling the common orifice of the bile and 
pancreatic ducts observed in the investigated cat specimens, agreed with NAV (2017) in the same animals as well as in the guinea pig (Stan, 2013).

In cats, a linear multifrequency transducer with working frequency $7.5 \mathrm{MHz}$ was used to scan cat's liver which nearly agreed with Mannion and Lang (2008) and Brioschi et al. (2014) who also declared using the same range of frequency but with a curved array transducer for abdominal ultrasonography in cats. Meanwhile, Lamb (1990) offered using a $5 \mathrm{MHz}$ transducer. Our examination on the liver was performed while the animals in dorsal recumbency as asserted by (Lamb, 1990; Partington \& Biller 1996 and Dennis et al. 2010) in cats. However, other authors recommended using a combination of positions; right lateral, left lateral and dorsal recumbency (Mannion, 2008 and Kealy et al. 2011) and Mannion (2008) who added that the gall bladder was better detected with the animal in lateral recumbency.

In the current study, the ultrasonographic approach was trans abdominal percutaneous epigastric in cats this approach was in consent to Banzato et al. 2015. However, the liver was observed from a ventral abdominal approach (Dennis et al. 2010) or by placing the transducer just caudal to the xiphisternum (Lamb, 1990 and Dennis et al. 2010) or beneath the costal arch (Burk \& Feeney, 2003). All whoever agreed that the liver could be accessible unlike what was proposed

J. Vet. Anat. that the ultrasonographic examination of the liver was difficult due a portion of the liver being obscured by the overlying stomach (Burk \& Feeney, 2003).

In the present investigation in cat, in the right medial hypo-chondral transverse scan, the identification of the anechoic gall bladder with distinct echogenic wall contributed to the determination of the two bordering lobes of the liver; the quadrate and the right medial lobes. The observation of the gall bladder was in accordance to that of (Mannion, 2008; Dennis et al. 2010 and Brioschi, et al. 2014) but was not recorded in the statement of Burk and Feeney (2003) and Santos (2014) who announced that the gall bladder wall was poorly visualized or not identified at all. Incoherence to the anatomic description of the feline gall bladder, it varied considerably in shape and size as approved by Burk and Feeney (2003).

Having the opinion that the intrahepatic bile ducts could not be evident on a general ultrasonographic examination in normal cats as that demonstrated by (Burk and Feeney, 2003; Dennis et al. 2010; Kealy et al. 2011).

\section{Conclusion}

Three main forms were collected; single gall bladder, duplex fundus and bilobed gall bladder. The single gall bladder with different shapes; relatively large oval or pear shaped or distended fundus or truncated fundus. In some forms of gall bladder were out 
stretched nearly to the level of the liver ventral borders. Both the gall bladder forms and the hepatic ducts distribution were not related. The bile duct was constructed from the left and right hepatic ducts in addition to the cystic one. In some cases, we explored that a short common hepatic duct by the union of the previous two hepatic ducts, and joined with the cystic duct establishing the bile duct. In the present study, the caudate process branch and the right lateral branch, each drained its respective hepatic portion. Commonly, these two branches merged to form a single duct that could be named right accessory hepatic duct which entered the "original" right hepatic duct of the right medial lobe. The sonographic investigation of the gall bladder was mainly confined to the left medial hypochondriac, middle xiphoid and right medial hypochondriac epigastric region. The gall bladder in cat was varied in conformation, bordered by the right medial lobe laterally and the quadrate lobe medially surrounded by echogenic wall.

\section{Acknowledgment}

We would like to give a voice to professor doctor Salah Mohamed Hagrass; professor of Anatomy and Embryology, faculty of veterinary medicine, Cairo University, for his valuable and constructive work.

\section{References}

Banzato, T., Bellini, L., Contiero, B., Selleri, P. and Zotti, A. (2015):
Abdominal ultrasound features and reference values in 21 healthy rabbits. Veterinary Record 4:176.

Brioschi, V., Roussetm, N. and Ladlow, J.F. (2014): Imaging Diagnosis-Extrahepatic Biliary Tract Obstruction Secondary to A Biliary Foreign Body in a Cat. Vet Radiol Ultrasound 55(6):628-63.

Brockman, D.J. (2013): Surgery of the Extrahepatic Biliary Tract in Cats and Dogs. World Small Animal Veterinary Association World Congress Proceedings. $38^{\text {th }}$ annual congress, Auckland, New Zealand.

Budras, K. and Habel, R.E. (2003): Bovine anatomy, An illustrated text, Sclutersche publisher.

Burk, R.L. and Feeney, D.A. (2003): Small Animal Radiology and Ultrasonography: A Diagnostic Atlas and Text, SAUNDERS, Elsevier Science, USA.

Center, S.A. (2009): Diseases of the gall bladder and biliary tree. J. small animal practice; 39(3):543-598.

D'Anjou, M.A. and Penninck, D. (2015): Liver. In: Penninck DG and D'Anjou MA (eds). Atlas of small animal ultrasonography, 2nd ed. Ames, IA, Blackwell Publishing, pp 220-222.

Dennis, R., kirberger, R.M., Barr, F. and Wrigley, R.H. (2010): Handbook of Small animal Radiology and Ultrasound, Techniques and Differential Diagnoses, $2^{\text {nd }}$ edition, Elsevier Limited.

Dyce, K.M., Sack, W.O. and Wensing, C.J.G. (2010): Textbook of 
veterinary anatomy, 4th Ed. Saunders, London.

Ergin, I., Senel, O.O., Sen, Y. and Bumin, A. (2013): Bilobed gallbladder in a cat. Revue Méd. Vét.;164 (10):453456.

Kealy, J.K., McAllister, H. and Graham, J.P. (2011): Diagnostic Radiology and Ultrasonography of the Dog and Cat, $5^{\text {th }}$ edition, by Saunders, an imprint of Elsevier Inc.

Kook, P.H. (2013): Gall bladder diseases in dogs and cats. Research gate, Clinic for Small Animal Internal Medicine, Vetsuisse-Faculty, University of Zurich, Zurich, Switzerland.

Lamb, C.R. (1990): Abdominal ultrasonography in small animals: Examination of the liver, spleen and pancreas. Journal of Small Animal Practice; 31: 615.

Lehner, C.M. and McAnulty, J.F. (2010): Management of extrahepatic biliary obstruction: A role for temporary percutaneous biliary drainage. Compendium: continuing education for veterinarians.

Mahato, N.K. (2010): Septate gallbladder: gross and histological perspectives in an uncommon occurrence. Int. J. Anatom. Variat.: 3, 70-72.

Mannion, P. (2008): Diagnostic ultrasound in small animal practice. Chapter 5: the liver and spleen, Published by john Wiley and sons, pp 50.

Mannion, P. and Lang, J. (2008): Diagnostic ultrasound in small animal practice. Chapter 4: Imaging of the general abdomen, Published by john Wiley and sons, pp 38.

Mayhew, P.D., Holt, D.E., McLear, R.C. and Washabau, R.J. (2002): Pathogenesis and outcome of extrahepatic Biliary obstruction in cats. J. small anim pract; 43:247-25.

Meyer, T. (2013): Primary liver cancer. Br. J. Cancer; 108 (4):995-996.

Nomina Anatomica Veterinaria NAV (2017): The International Committee on Veterinary Gross Anatomical Nomenclature, Published by the Editorial Committee Hannover (Germany), Columbia, MO (U.S.A.), Ghent (Belgium), Sapporo (Japan), $6^{\text {th }}$ edition (Revised version).

Partington, B. and Biller, D. (1996): Liver In: R. Green (Editor) Small Animal Ultrasound, chapter 6. LippincotRaven Publishers, Philadelphia, pp. 105-130.

Penninck, D.G., Brisson, J.O. and Webster, C.R.L. (2010): Sonographic assessment of gallbladder volume in normal cats. Vet Radiol Ultrasound; 51: 665-666.

Santos, D.C.D. (2014): Ultrassonografia Abdominal De Gatos Pediatricos Higidos. Master Thesis. Universidade Federal De Lavras, Brazil.

Stan, F.G. (2013): Comparative study of the stomach morphology in rabbit and chinchilla. Agro life scientific journal, Bucuresti, Romania;2:73-78. 


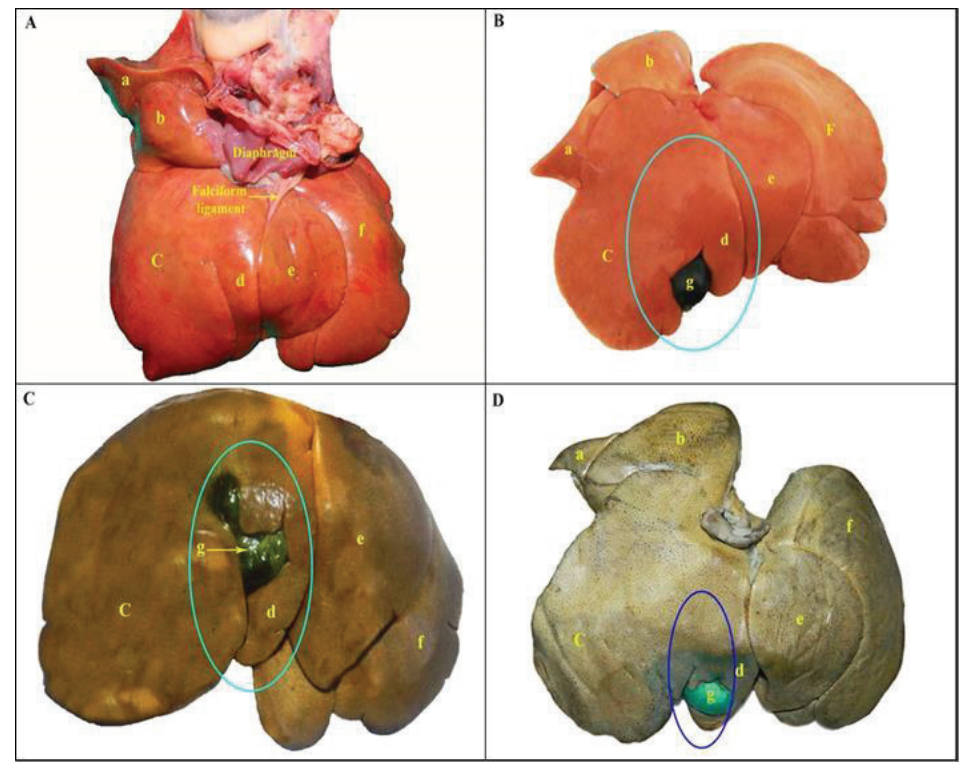

Fig. (1): A photograph showing the position of the gall bladder on the parietal surfaces of the cat's liver.

A. Gall bladder does not appear on parietal surface in the large oval and pear-shaped single ones. B.C.D. Gall bladder appeared parietally in distended fundus, truncated fundus and bilobed gall bladder, respectively.

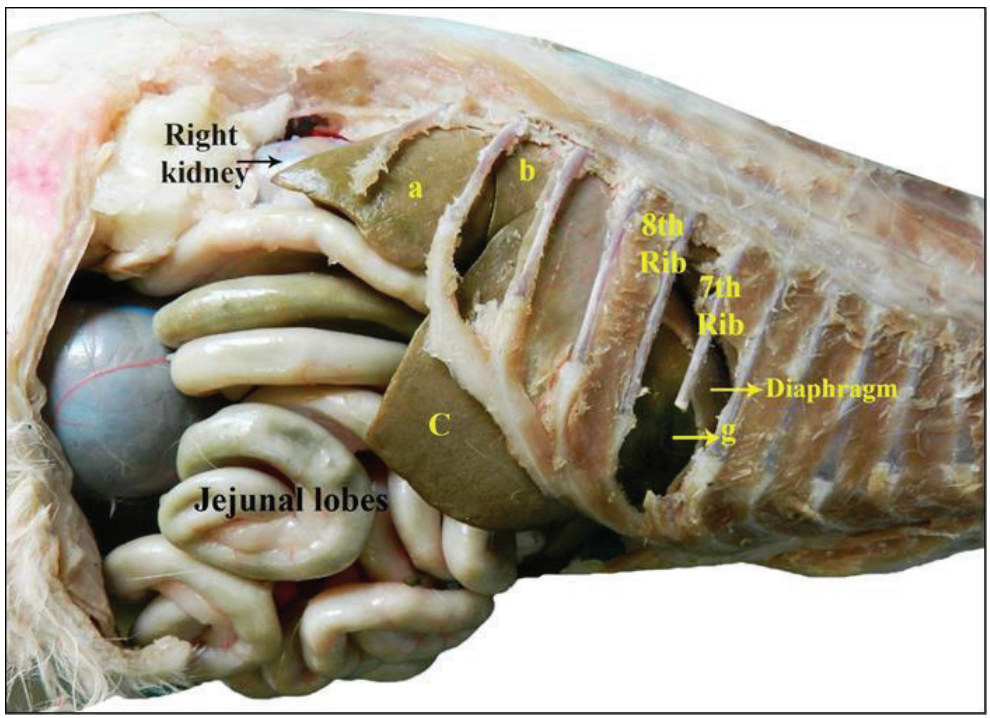

Fig. (2): A photograph showing the position of the gall bladder of cat on the parietal surface of the liver at the level of the $7^{\text {th }}$ intercostal space. 


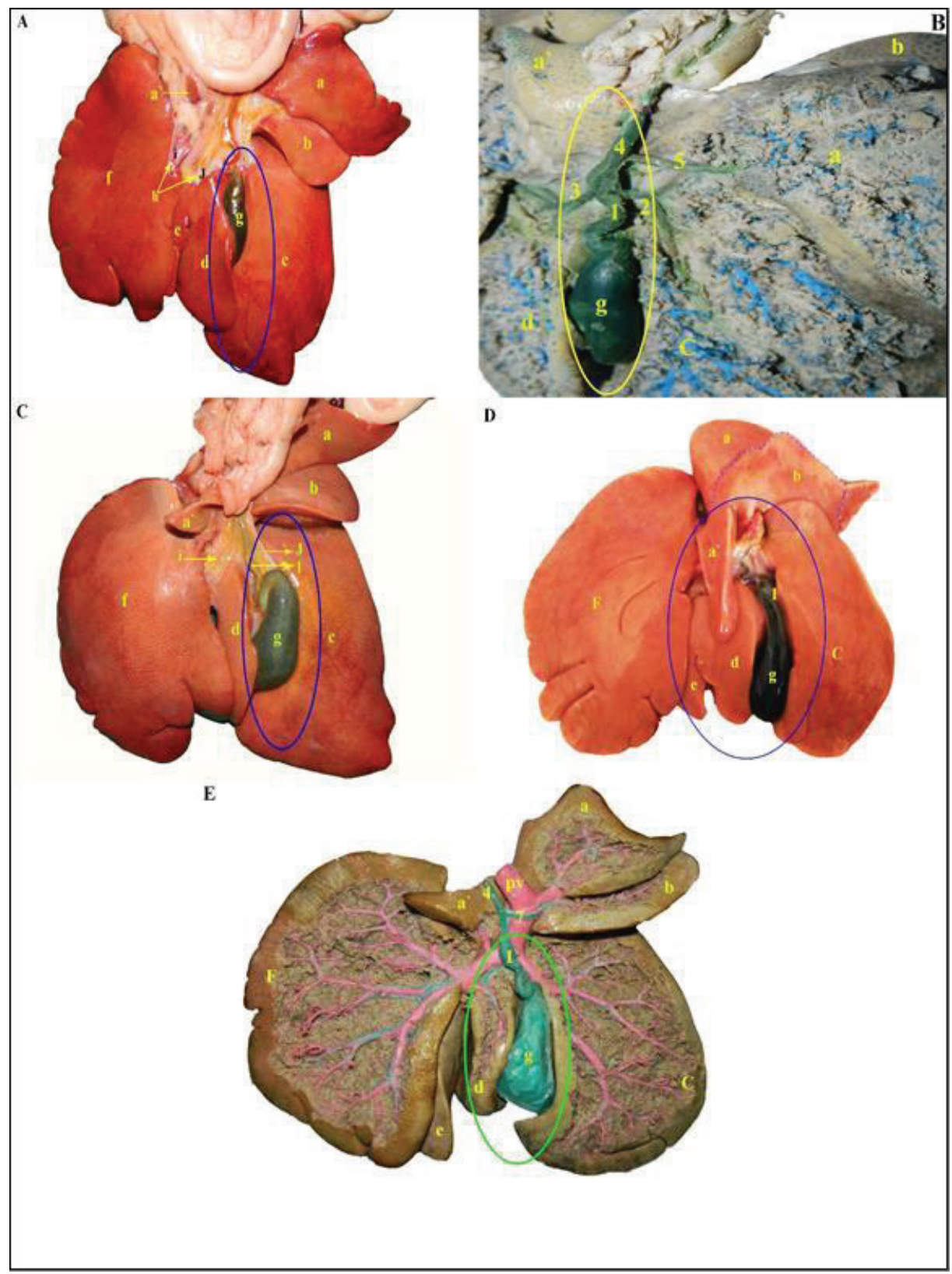

Fig. (3): A photograph showing different shapes of single cat gall bladder.

A.B. relatively large oval gall bladders, C. pear shaped, D. distended large fundus, E. Truncated fundus 


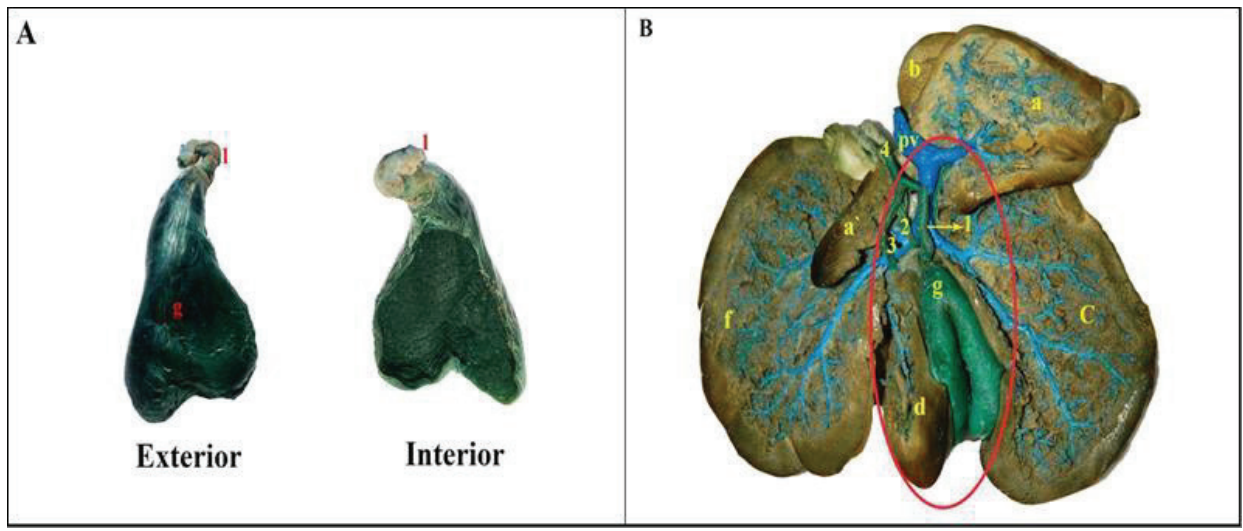

Fig. (4): A photograph showing the duplex fundus gall bladder $(A)$ and the bilobed cat gall bladder (B).

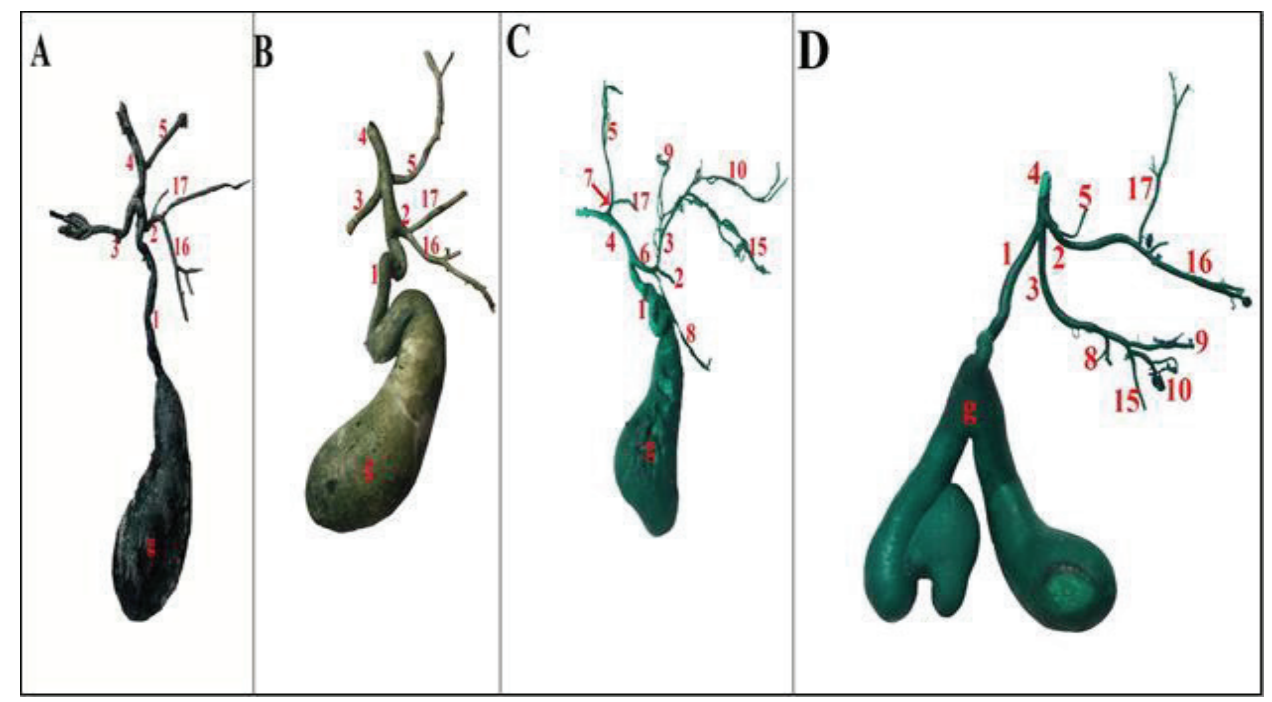

Fig. (5): Latex neoprene cast of the cat biliary system isolated;

$(A, B, D)$ : Bile duct formed by the left and the right hepatic ducts with the cystic duct, (C): Bile duct formed by the union of the cystic duct with the common hepatic duct. 


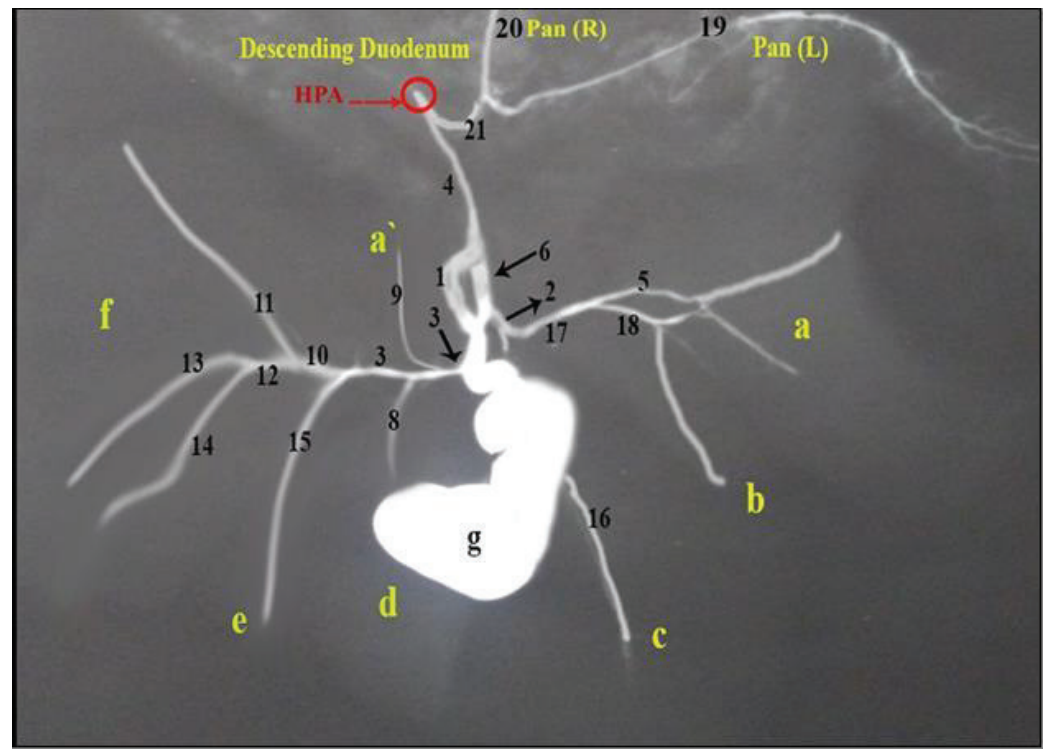

Fig. (6): X-ray film showing the termination of the hepatic ducts and the formation of the bile duct which united with the main pancreatic duct to open on the major duodenal papilla surrounded by Hepatopancreatic ampulla in cat.

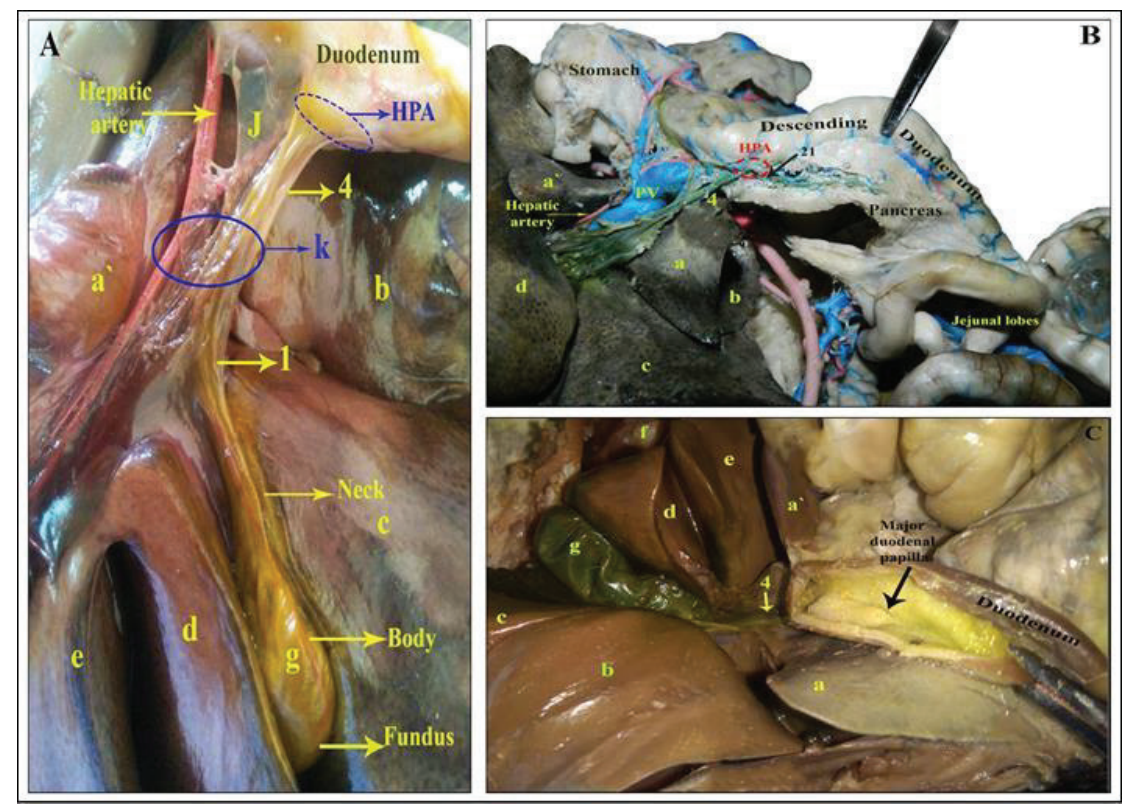

Fig. (7): A photograph showing the course of the bile duct in the hepatoduodenal ligament $(A)$, its union with the main pancreatic duct $(B)$ and its opening on the major duodenal papilla (C) surrounded by the Hepatopancreatic ampulla in cat 
Legends for figs. $(1-7)$ in Cat:
a. Processus caudatus; Lobus caudatus
a' Processus papillaris; Lobus caudatus
b. Lobus hepaticus dexter lateralis
c. Lobus hepaticus dexter medialis
d. Lobus quadratus
e. Lobus hepaticus sinister medialis
f. Lobus hepaticus sinister lateralis
g. Vesica fellea
h. Lesser omentum
i. Hepatogastric ligament
J. Hepatoduodenal ligament
k. Porta hepatis
HPA: Hepatopancreatic ampulla
Pv: Portal vein
Pan (R): Right pancreatic lobe
Pan (L): Left pancreatic lobe

\author{
1. Ductus cysticus \\ 2. Ductus hepaticus dexter \\ 3. Ductus hepaticus sinister \\ 4. Ductus choledochus \\ 5. Ramus processus caudatus \\ 6. Ductus hepaticus communis \\ 7. Ductus hepaticus dextra accessoria \\ 8. Rr. lobi quadrati \\ 9. R. omentalis \\ 10. Ramus lobi sinistri laterales \\ 11. R. dorsalis lobi sinistri lateralis \\ 12. Truncus communis \\ 13. R. intermedius lobi sinistri lateralis \\ 14. $R$. ventralis lobi sinistri lateralis \\ 15. $R$. lobi sinistri medialis \\ 16. R. Iobi dexter medialis \\ 17. R. lobi dexter lateralis \\ 18. Rr. lobi dexter lateralis \\ 19. Left pancreatic duct \\ 20. Right pancreatic duct \\ 21. Main pancreatic duct
}

\section{*Corresponding author:}

Reem R.T.

Department of Anatomy and Embryology, faculty of veterinary medicine, Cairo University, Egypt.

\section{reemtahon@gmail.com}




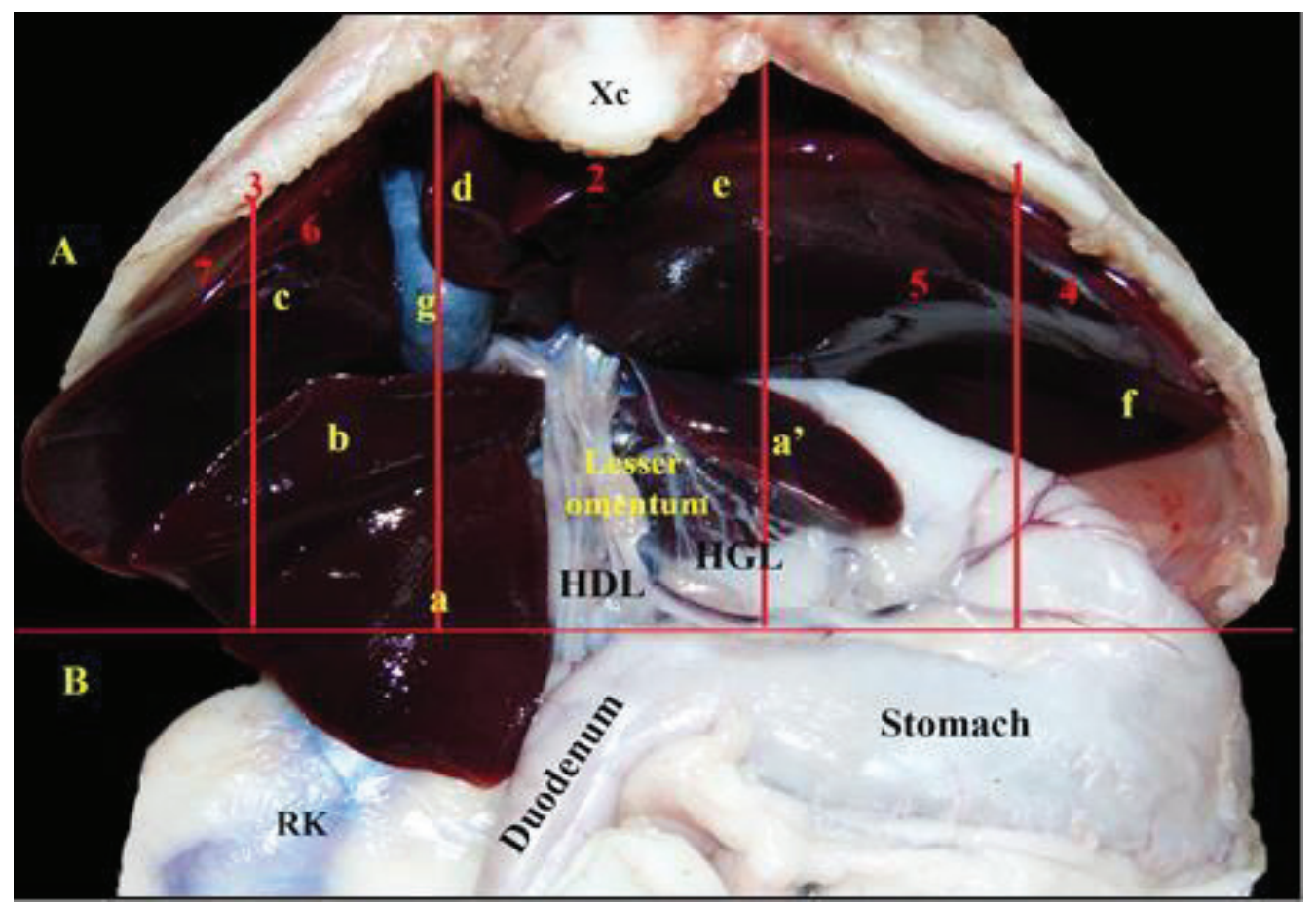

Fig. (8): A photograph showing the topographic description of the abdominal regions and cat liver in situ.

A. Epigastric abdominal region $\quad$ B. Meso-gastric abdominal region

1. Left hypo-chondral epigastric region

2. Middle (Xyphoid) epigastric region

3. Right hypo-chondral region

4. Left lateral hypo-chondral epigastric region

5. Left medial hypo-chondral epigastric region

6. Right medial hypo-chondral epigastric region

7. Right lateral hypo-chondral epigastric region

HGL: Hepatogastric ligament of Lesser omentum

HDL: Hepatoduodenal ligament of Lesser omentum

a: Caudate process of caudate hepatic lobe

a': Papillary process of caudate hepatic lobe'

b: Right lateral hepatic lobe

c: Right medial hepatic lobe

d: Quadrate hepatic lobe

e: Left medial hepatic lobe

f: Left lateral hepatic lobe

g: Gall bladder 


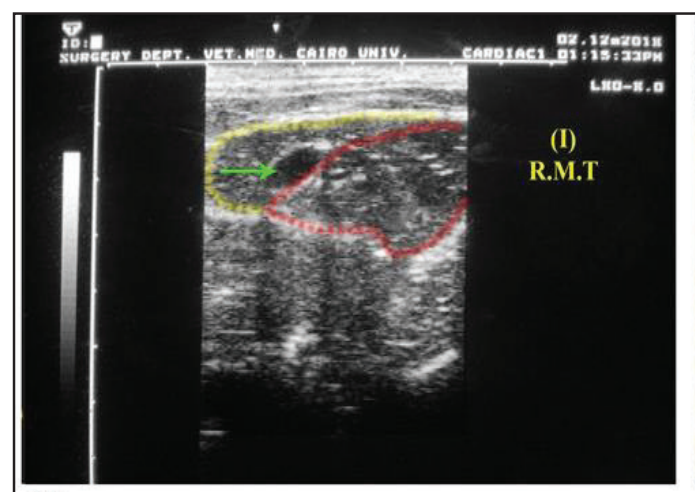

(a)

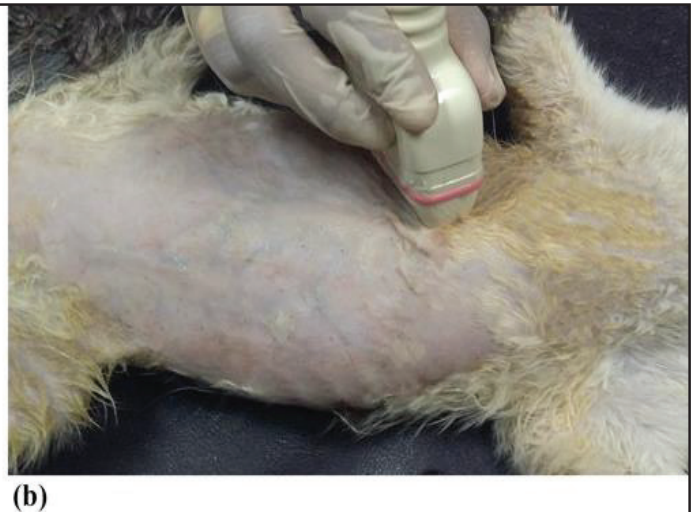

(b)

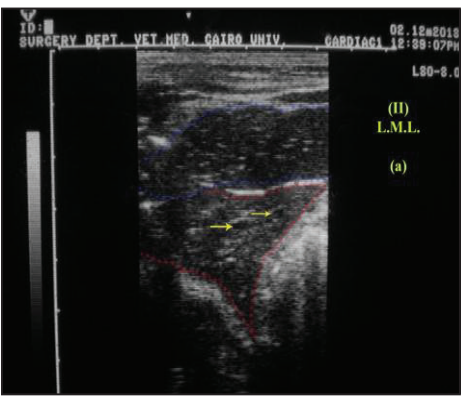

(b)

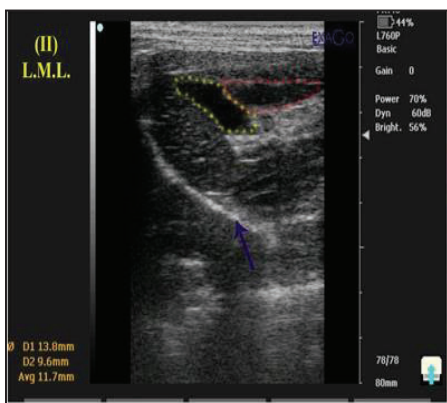

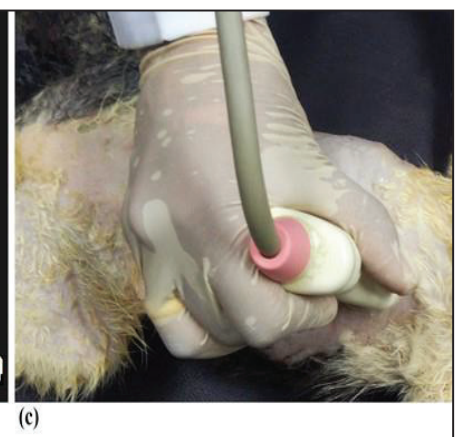

Fig. (9): (I) Right Medial Transverse (RMT) ultrasound scan in cat showing;

a. Hypoechoic Right medial (red dots) and quadrate (yellow dots) lobes with a green arrow pointing at the gall bladder appearing with anechoic lumen surrounded by echogenic wall, situated between them.

b. Location and direction of linear transducer (Right medial hypo-chondral epigastric transverse).

(II) Left Medial Longitudinal ultrasound scan showing;

a. In case of extended stomach, no trace of gall bladder was observed, only the hypoechoic heterogenous left lateral and left medial lobes appeared outlined by red and blue dots, respectively. The yellow arrows are pointed at the C/S of the branches of $V$. hepatica lobi sinistri lateralis appearing anechoic lumen without echogenic wall.

b. In case of empty stomach, the pear-shaped anechoic gall bladder (yellow dots) appeared surrounded by echogenic wall in close relation to only the hypoechoic quadrate lobe appeared outlined by red dots. Noted the blue arrow pointed at the echogenic diaphragm.

c. Location and direction of linear transducer (Left medial hypo-chondral epigastric longitudinal).

d. (Left medial hypo-chondral epigastric longitudinal). 


\section{Animal species in this Issue}

\section{Domestic cat (Felis catus or Felis silvestris catus)}

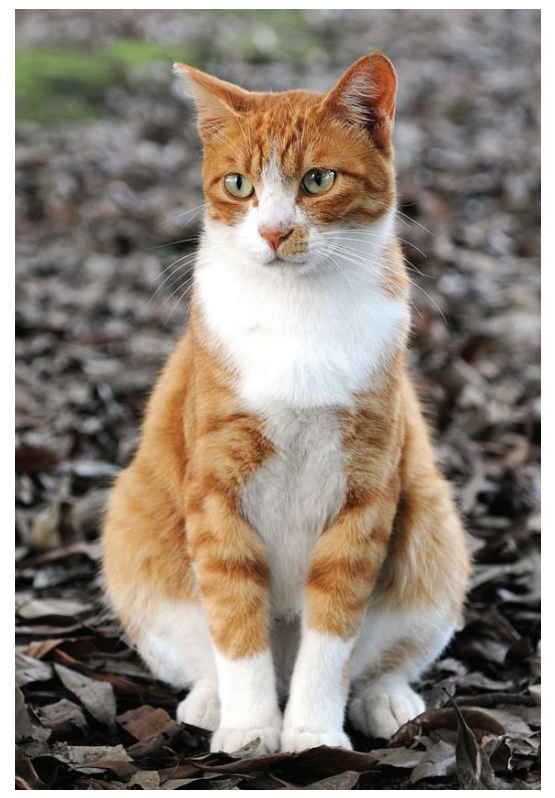

Kingdom: Animalia \& Phylum: Chordata \& Class: Mammalia \& Order: Carnivora \&

Family: Felidae \& Genus: Felis \& Species: F. catus

The domestic cat is a small, usually furry, domesticated, and carnivorous mammal. It is often called a housecat when kept as an indoor pet. Cats are similar in anatomy to the other felids, with strong, flexible bodies, quick reflexes, sharp retractable claws, and teeth adapted to killing small prey. Cat senses fit a crepuscular and predatory ecological niche. Cats can hear sounds too faint or too high in frequency for human ears, such as those made by mice and other small animals. They can see in near darkness. Like most other mammals, cats have poorer color vision and a better sense of smell than humans.

The cat skull is unusual among mammals in having very large eye sockets and a powerful and specialized jaw. Within the jaw, cats have teeth adapted for killing prey and tearing meat. When it overpowers its prey, a cat delivers a lethal neck bite with its two long canine teeth, inserting them between two of the prey's vertebrae and severing its spinal cord, causing irreversible paralysis and death

Source: Wikipedia, the free encyclopaedia 